\section{ULTRASONOGRAPHY: how to raise the impact factor}

JEONG-SIK YU

Editor-in-Chief ULTRASONOGRAPHY

Since 2014, when we renamed the official journal of the Korean Society of Ultrasound in Medicine (KSUM), Ultrasonography has been published in English only with a full Open Access policy, and the number of citations of Ultrasonography articles by articles in other journals has increased [1]. All of the e-published articles in the "ahead-of-print" status as well as all officially issued articles are searchable in PubMed (https://www.ncbi.nlm.nih.gov/ pubmed?term=Ultrasonography[jour]), and the early indexing in PubMed has contributed to maximizing the span of time our articles appear to global readers.

The impact factor (IF), reflecting the citation rate of the articles in a journal in a certain period of time, is generally used to validate a journal among the journals in the same field of interest. It is likely that most journal editors are concerned about increasing their journal's IF. About 80 articles published in the first two years (2014-2015) of Ultrasonography were cited more than 200 times by the articles in the Web of Science Core Collection up through this November. When we estimated the citation rate of the 40 Ultrasonography articles published in 2014 using an IF calculation method similar to that used by the Journal Citation Reports (JCR), we found 73 citations from the Web of Science Core Collection articles published in 2015; and the citation rate was 1.825. From the official 2015 JCR (https://jcr. incites.thomsonreuters.com/), we found two journals having higher IFs (Ultraschall in der Medizin, IF=4.434; Ultrasound in Medicine and Biology, IF=2.298) than the citation rate of Ultrasonography in the field of general clinical ultrasound. Although the scale of coverage of the societies that sponsor these two journals, the European Federation of Societies for Ultrasound in Medicine and Biology (EFSUMB) and World Federation for Ultrasound in Medicine and Biology (WFUMB), is not comparable with KSUM, and the total number of published articles is more limited in Ultrasonography, we need to preserve or further increase the citation rate to achieve global name recognition.

As a matter of fact, well-designed and well-written articles dealing with current popular topics tend to be more frequently cited than others, and such articles can be selected and qualified from a large pool of submitted articles. Toward this goal, a large number of

\section{Jeong-Sik Yu, MD}

Deparment of Radiology, Gangnam Severance Hospital, Yonsei University College of Medicine, 211 Eonju-ro, Gangnam-gu, Seoul 06273, Korea Tel. +82-2-2019-3510, Fax. +82-2-3462-5472, E-mail: yjsrad97@yuhs.ac

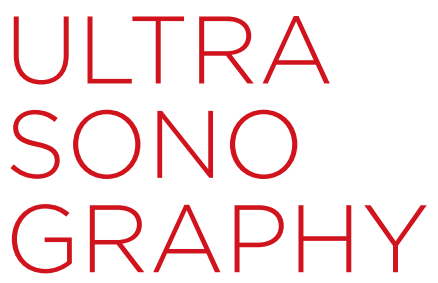

\section{EDITORIAL}

https://doi.org/10.14366/usg. 13047 pISSN: 2288-5919 • elSSN: 2288-5943 Ultrasonography 2017;36:1-2

Received: November 23, 2016

Revised: November 26, 2016

Accepted: November 30, 2016

This is an Open Access article distributed under the terms of the Creative Commons Attribution NonCommercial License (http://creativecommons.org/ licenses/by-nc/3.0/) which permits unrestricted noncommercial use, distribution, and reproduction in any medium, provided the original work is properly cited.

Copyright (C) 2017 Korean Society of Ultrasound in Medicine (KSUM)

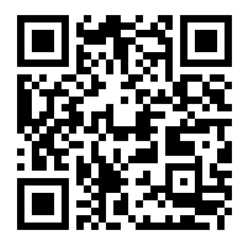

How to cite this article:

Yu JS. ULTRASONOGRAPHY: how to raise the impact factor. Ultrasonography. 2017 Jan; $36(1): 1-2$. 
domestic and global submissions should be more actively encouraged. However, it is not easy to provoke an increase in the number of submissions to Ultrasonography because although we are indexed in the Web of Science Core Collection via the Emerging Sources Citation Index (ESCl), we are still waiting for indexing in the Science Citation Index Expanded (SCIE). In the meantime, some strategies are needed to raise the citation rate of Ultrasonography.

Until this November, 22 Review Articles published during the first 2 years (2014-2015) have been cited 111 times while 42 Original Articles and 14 Case Reports of the same time period have been cited 92 and six times, respectively, by articles in the Web of Science Core Collection (http://apps. webofknowledge.com/). Above all things, we should more actively offer the opportunity to submit Review Articles on current popular topics fitting the scope of Ultrasonography to the international and domestic lecturers invited to the Annual Meeting of KSUM [2-5]. Besides global advertising of our free mobile app service for all journal contents and monthly e-mailing of the Table of Contents of recently published articles, we are going to publicly recognize several distinguished domestic articles to attract our society members' attention. We have realized that Case Reports negatively affect the overall citation rate of Ultrasonography. For the purpose of increasing the IF, we decided to temporarily exclude Case Reports from the categories of articles we accept, and we will publish 12-14 Review Articles and 25 or more Original Articles as the journal's core articles annually in Ultrasonography beginning in 2017. On behalf of the Editorial Board, I invite researchers from around the world to submit high quality articles to our journal, which will be rewarded by a high IF in the near future.

ORCID: Jeong-Sik Yu: http://orcid.org/0000-0002-8171-5838

\section{References}

1. YU JS. ULTRASONOGRAPHY: two years of globalization and the achievement of ESCl status. Ultrasonography 2016;35:1-2.

2. Russ $\mathrm{G}$. Risk stratification of thyroid nodules on ultrasonography with the French TI-RADS: description and reflections. Ultrasonography 2016;35:25-38.

3. Nolsoe CP, Lorentzen T. International guidelines for contrastenhanced ultrasonography: ultrasound imaging in the new millennium. Ultrasonography 2016;35:89-103.

4. Kamata K, Kitano M, Omoto S, Kadosaka K, Miyata T, Minaga $K$, et al. New endoscopic ultrasonography techniques for pancreaticobiliary diseases. Ultrasonography 2016;35:169-179.

5. Valluru KS, Willmann JK. Clinical photoacoustic imaging of cancer. Ultrasonography 2016;35:267-280. 